\title{
Outcomes of Gender Discrimination, A Study of Female Workers in Banking Sector of Pakistan.
}

\author{
Mustafa Khalid ${ }^{1}$, Rabail Aroosh ${ }^{2}$ \\ ${ }^{I}$ (Department of Management \& Economics, Foundation University Rawalpindi Campus, Pakistan)
}

\begin{abstract}
The study reveals the concept of gender discrimination at workplace and how it affects the performance of female employees and as a result its impact on organizational performance in banking sector of Pakistan. Data was collected from both males and females working in private banks through questionnaires. According to the results, we concluded that gender discrimination has not as such impact on employee performance and organization commitment and culture moderated the relationship between gender discrimination and organizational commitment.
\end{abstract}

Keywords: Gender Discrimination, Employee Performance, Banking Sector of Pakistan, Organizational Commitment, Culture.

\section{Introduction:}

Gender discrimination is a global phenomenon which can be observed at personal and organizational level. "Gender gap is defined as deviations from the ideal, which is a genderless society, i.e. a society in which men and women would participate in more or less equal numbers in every sphere of life, from infant care to high-level politics"(Öhman et al, 2007).Gender discrimination is the result of historically generated gender perceptions in which the differentially assigned male female qualities were unevenly designed in layers of privileged and subordinate positions of male and female abilities (Ertürk, 2004).

In recent decades unstable economic conditions, social and family challenges and increased literacy rate among females in a developing country like Pakistan endorsed more job opportunities for females at work place. This evolves various challenges for decision makers to develop a more gender balance environment (Irfan, Hussain\&Yousaf, 2009).In fact, it has gradually become more evident to organizations that Discrimination within organization is a serious and crucial dilemma that needs to be concentrated on (Gelfand, Nishii, Raver \& Schneider, 2007). Females are treated unsymmetrical and unfairly which is evident by numerous studies which shows that at work place men are given privileged over women for hiring and promotion opportunities. By this way female skills are underutilized which lowers economic efficiency (Tianhu and Huang 2010). Hence women are treated unfair and unequal. Due to this reason, morale of female employees decreases. It effects not only organizational efficiency but economic efficiencies as well as capabilities of women are not utilized up to their best (Pang and Huang, 2010). It is common practice which can be observed in our daily lives that an educated and qualified female manager would lose a promotion and less deserving and less experienced male colleague would get it, for instance, or a talented female executive would be demoted after her maternity leave. Females' exposure to discrimination is more obvious especially in Muslim countries (Cooray and potrafke, 2010).

Throughout the world, up to some extent, it is perceived that male part of the society is more productive and efficient as compared to female part. Gender discrimination is seen in manufacturing organizations at not only wage distribution but at the time of wage setting as well. It is therefore, recommended to all organizations whether services or manufacturing concern that the healthy work environment without gender discrimination ultimately increases the productivity of the employees as well as of an organization (Abbas, Athar, and Herani, 2010).In fact, there are several workplace barriers which women faces few of them were turnover, promotion barriers, lack of consistency, work stress, Managing Family Responsibilities, Job Qualities, and Work Schedule Flexibility and most importantly Discrimination.(Allen, Armstrong, Riemenschneider\& Reid, 2006). In developing country there are several cultural barriers to gender impartiality that confines their growth opportunities. (Jutting and Morrisson, 2005).Tianhu and Huang(2010) says there are no of factors influencing Chinese concept of gender discrimination some of them are law, education and traditional family culture and can help to improve gender conception.

It is a strong belief by many people that discrimination from their supervisor in terms of race or gender or they might have experiences discrimination at the organizational level in terms of policies and procedures, are less satisfied with their job and less committed to their organization (Welle and heilman,, 2005). Research by Bravo,Sanhueza\&Urzúa (2005) further provide evidence that in the Chilean labor market gender discrimination plays a critical role in determining the wages of work force. According to Qureshi, Zaman and Shah (2010) a known phenomena in human resource management is the influence of rewards on employee performance and 
various studies states that rewards plays a significant role in increasing employee performance. Therefore we can say Gender discrimination and employee performance are directly proportional and by implementation of proper gender discrimination policy within an organization help to attain increase employee performance, motivation and satisfaction (Abbas, Athar, Herani, 2010).

The objective of this study is to analyze the outcomes of gender discrimination specific to females in banking sector of Pakistan. The more explicit objective is to find out the effect of gender discrimination on employee performance and commitment. By studying a number of researchers, we found out a gap in the study i.e. the researchers were unable to identify any positive side of gender differences. As said by LippertRasmussen (2006) that inequality between men and women is a criterion for the existence of bad discrimination. Hence, in our study we came up with its positive side restricted to the culture of Pakistan. We studied that how Pakistani traditional family culture can influence gender discrimination. Pakistani women are given relaxations in their working hours and also burden of work. We cannot see such leverage in any other country. In the study we are also going to discuss how this positive aspect of culture will have an impact on female employees and overall organization as well.

\section{Gender Discrimination:}

\section{Literature Review:}

Discrimination can be defined as age, racist or sexist prejudice, which involves treating people in a different way on the basis of their P-properties (including age, sex and race), in an ethically objectionable way (Lippert-Rasmussen, 2006). Treatment Discrimination outcomes in differences in job results between two groups similar in work experience, education, and skills after access occurs (Truman and Baroudi, 1994). It can also be defined as the work done by women is valued less than the work done by men, this could explain why there are differences between pay but no differences in title (Truman and Baroudi, 1994). Direct discrimination is further divided into two categories cognitive and non cognitive discrimination. When people have biased beliefs toward certain people that is a result of cognitive discrimination e.g. while comparing capabilities of both men's and women's for a manager's position these people believe that men are more capable then women for this particular position. Similarly non cognitive discrimination occurs when this kind of biased belief evident itself in behaviors e.g. these people will more likely prefers the subordinates or company of members of their own race (Lippert-Rasmussen, 2006). Ridgeway and Correll, 2004 further said, Similar to other kinds of differences and disparity like those based on race, class, gender discrimination is further divided into different levels i.e. cultural values and resources at the macro level, Behaviors and organizational practices at the international level, and individuality at the individual level. Labor market sector differences and levels of workplace isolation seem more supreme for understanding employment inequality (Roscigno, Garcia, and Bobbitt-Zeher, 2007). Another important concept related to gender discrimination is gender mainstreaming, which we describe as efforts to examine and reinvent processes of policy formulation and execution across all issue areas to address and correct persistent and rising disparities between men and women (True and Mintrom, 2001). As rising numbers of women entered the workforce, long-standing stereotypes and perceptions were upended and cultural images corrected (Lens, 2003). Gendered assumptions and their connection to discrimination with women being variously explained as less intelligent, hormonal, and sensitive. Such assumptions about women, when joint with gender typing of jobs, lead to blocked opportunities (Roscigno, Garcia, and Bobbitt-Zeher, 2007). Hass and Huwang in 2007 also calculated women's existence in top management by asking how many women and how many men were in top management. Two-thirds of companies (68 percent) had no women in top management; the highest percentage of women who were managers was 8 , and the average percentage was just 4.3. Changes in the place of women in the labor market are related to changes in the place of women in the family and again exemplify the interconnections between processes of production and consumption (Bondi, 1991).

Gender differences and wage inequality in human capital explicate only a part of the workplace authority gap, leaving most of it unexplained (Huffman and Cohen, 2004). Gender has been a basic aspect of work organizations in industrial societies. Employers suppose men are more accountable than women for family income provision and that involvement in paid work is their chief life pursuit (Haas and Hwang, 1995). Women get lower salaries than men even when job age, level, education, and work experience are restricted (Truman and Baroudi, 1994). Women have never been more than a small portion of the CEOs of Fortune 500 companies. In 2004, eight women were 1.6 percent of the CEOs of these companies (Acker, 2006). Those in gender-isolated professions, such as nurturing and teaching, should be permitted to higher compensation, not because their jobs are essentially equal to men's, low pay is a reflection of the lower esteem in which so-called female professions are held in society(Lens, 2003). Most of the female employees, in fact, this question was notappropriate; they worked in female dominated occupations and in areas of bank where their investment in a particular version of femininity was taken for granted both by the women and their male colleagues, or, more often, male superiors (McDowell and Court, 1994). Most women worldwide face related obstacles in increasing their economic 
Outcomes of Gender Discrimination, a Study of Female Workers in Banking Sector of Pakistan.

power: no "slack" time to spend on additional work that could bring in much needed income; lack of access to commercial credit; and training in conventionally female-and more often low wage- skills. These obstacles make a distinction between work experiences of men and women, worsen women's poverty, and sustain a vicious cycle of impoverishment from one generation to the next (Buvinić, 1997). Sometimes solo fathers, like solo and conventional mothers, experience social segregation, income loss and career restrictions as a result of primary responsibility for child care (Rossi, 1984).

Gender inequality is widely recognized as a significant factor in the spread and entrenchment of poverty (Schech and Dev, 2007). Poverty is a state of being, whereby people in short of (a) income and assets to gain basic requirements, (b) power and voice in the institutions of society and state, (c) freedom and a level playing field to live their lives on basis of justice and equality and( d) are vulnerable to adverse shocks and unable to deal with them. As poverty is a result of as much a lack of power and voice as of material resources, empowerment of women and other deprived groups is a precondition to breaching the vicious circle of poverty and voiceless status (Acharya and Ghimire, 2005). Ironic outcome of female and export led Asian industrialization is that they do not essentially boost women's requirements for education but considerably change their economic independence and role in the family (Ross, 1989). "If you educate a boy you educate a human being. If you educate a girl, you educate generations."(Buvinic, 1997). Women are occupied in employment, i.e. income earning associated with the market, there will be an improvement in their status (Shah et al, 1994). Empowerment of women has to go further than mere instrumentalism and start with first addressing questions of women's agency, their comfort and self-worth and then that of their families and communities (Kelkar, 2005). Not everyone possesses all of the characteristics associated with men. Likewise, not everyone possesses all of the attributes associated with women (Oswald and Lindstedt, 2006). Generally female employees are disadvantaged in case of opportunities for authority (Huffman and Cohen, 2004). When women were asked why they left their earlier employers, those who had been employed somewhere else gave a range of reasons including poor or improper management, travel, stress and/or burnout, responsibilities and family conflicts, pay, bad work environment, medical reasons, feeling unappreciated, seeking flexibility and the chance to learn, and company shutdowns. The women frequently gave examples of situations where they did not receive the respect they felt they deserved from outside clients, coworkers and managers (Allen et al, 2006). So in order to recruit, direct and retain the highly capable and skilled workforce is a demanding task for the firms hence there is a requirement to extend human resource management rules and procedures that encourage the females at workplace (Irfan, Hussain and Yousaf, 2009).

Gender and race inequalities in the labor market got considerable attention by researchers over the past twenty years (Roscigno, Garcia, and Bobbitt-Zeher, 2007). Feminization of the labor force has been reflective particularly in the last decade. In Britain, for instance, no less than eight out of ten new jobs formed in the 1980s have been for women (McDowell and Court, 1994). Diversity of race and gender within a store had no significant effect on sales, while age diversity forecasted lower sales (Leonard, Levine and Joshi, 2004). We studied country memberships in eight regional and global intergovernmental firms that were lively in promoting gender equality in the 1970s and 1980s and that established stage for action on gender mainstreaming during the 1990s (True and Mintrom, 2001). Supreme Court started benefit programs that had initially been enacted as defensive programs for women, such as mother's benefits, were redefined along with women's and men's roles. In fashioning its concept of equality in the benefits cases, the Court demonstrated a degree of elasticity, particularly when it was not easy to silent the differences between women and men by simply revising cultural roles. For example, the issue in Manhartinvolved a pension plan to which women were required to contribute more than men because they tend to live longer and, as a group receive more benefits than men (Lens, 2003). Women are on the board of directors, for instance, in two or three City banks, although various remain all-male bastions at this level. Generally, women dwell in a small proportion of senior positions in most areas of financial services. The only profession where their representation is significant at senior levels is in personnel services and human resources departments, where the "female" characteristics of caring for others give them a "natural" advantage (McDowell and Court, 1994). Trade increases wage inequity by discreetly reducing the relative wages of less-skilled workers, at the same time it appears to profit women by reducing the capability of firms to discriminate (Black and Brainerd, 2004). The preceding meta-analysis of gender wage discrimination also uncovers an important concluding of the gender space by roughly one percent per year from an average of more than 30 percent of the female wage (Jarrell and Stanley, 2004).In past, international advanced agencies such as the United Nations Development Programmes, the United Nations Food and Agricultural Organization, and the United States Agency for International Development have done much to be responsible for the western stereotype of women's place being solely in the home and nurturing her children. This is a role which in fact is unknown to most Third World women, including a majority of Pakistani women, who must also work hard in the fields or trade in the marketplace for their family's subsistence (Weiss, 1985). 
Outcomes of Gender Discrimination, a Study of Female Workers in Banking Sector of Pakistan.

\section{H1: Gender discrimination has a negative impact on organizational commitment of employees. Organizational commitment:}

Organizational commitment as defined by Bateman and Strasser (1984) states that organizational commitment is multidimensional in nature, involving an employee's loyalty to the organization, willingness to exert effort on behalf of the organization, degree of goal and value congruency with the organization, and desire to maintain membership. Abdullah et al. (2007) states that employee commitment to organization is of high worth. Commitment is fundamental to the productivity, quality and performance of organization. Evidence showing relationship between organizational commitment and job satisfaction has been found in large organizations. In order to achieve the higher level of organizational commitment the focus is to maintain job satisfaction which leads to increase in employee's productivity and as a result higher organizational commitment (Warsi, Fatima \&Sahibzada, 2009). WeiBo, Karurand Jun (2009) further discussed development of organizational commitment and its influence to organizational outcomes. Organization commitment and organizational effectiveness has a relative stronger relationship (Angle and Perr, 2007). The study by Machin and Bannon (2005) examined the link between organizational commitment and employee perception of their organizations climate. Amato and Hertzfeldt (2008) further highlight the role organizational commitment plays for talent retention.

Gender discrimination is consistently viewed as a crucial factor in determining various attributes for instance job satisfaction, job involvement, organizational commitment and many more (Sattar and Nawaz, 2011). The key influencing factor affecting employee commitment to organization, quality of work life and job satisfaction is perceived organization support (Saad, Samah and Juhdi, 2008). Women working in organization are proved more productive in performance of their organizational responsibilities in an indiscriminative, helpful work environment (Irfan, Hussain and Yousaf, 2009). Those women who themselves have experienced discrimination within their organization or have seen others been affected, are less committed towards their work (Welle, Heilmen, 2005). If women are believed to be committed towards organization but are constrained by family circumstances and men are not, women will not be given same considerations for promotion (Dukes, 2003). Ekmekçi (2010) further studied the males and females' different level of organizational commitment in view of society and this level of commitment differ because of discrimination women experience within the organization. Discrimination from supervisor, coworker and organization itself has an adversely affect on organizational commitment, job satisfaction and organizational citizenship behavior (Ensher, Vallone and Donaldson, 2001). According to Onay, Unirversitedi and Okulu (2009), women perception of gender discrimination is more than men and discrimination among workers affect organizational commitment and their intentions to leave the Job. Day (2000) further studied sexual harassment and gender discrimination and their significant relationship between organizational commitment and conflict between work and family. In order to have organizational commitment, there should be an indiscriminative work environment.

\section{H2: Gender discrimination has a negative impact on employee performance. Employee performance:}

Employee performance plays a very significant role in determining the progress of a company (Jain, 2008). The definition of performance is based on (Shahzad et al, 2010) who suggested that "Performance refers to as the results or impact of activities of an individual over a given time span". The four traits of employee performance in an organizational culture are consistency, involvement, adaptability, and mission which are also important predictors of other efficiency criteria such as employee satisfaction, quality, and overall performance (Denison and Mishra, 1995). Thought of a gender performance is particularly helpful in getting the construction and upholding of gender identities and gendered power associations in the workplace (McDowell and Court, 1994).

Research by Khera (2010) suggests that organizations need to manage their human resource effectively to get the maximum contribution of employees to organization achievement. Shahzads et al (2010) further states that for achieving overall goals of an organization, managing and improving employee performance are decisive because employee performance has a direct relation to organizations productivity and triumph. A report by General Accounting Office, Washington (1998), emphasis the importance of agencies addressing an HRM issues of management of employee performance and aligning with agencies goals and mission.

Employee performance depends on several indicators such as: increments, performance appraisal system, job security, job satisfaction, training and development, organization structure and so on (Ehsan, Ghafoor and Salman, 2011). On the other hand, a study by Qureshi, Zaman and Shah (2010) showed that there are no of factors affecting employee performance such as intrinsic, extrinsic rewards, well defined job description and a pessimistic impact of gender discrimination. Payment in regard of salary is a form of exchange between employers and employees for human capital services. Other forms of exchange could be non-monetary, such as promotions. Promotions lead to increase in job level. likely to the argument given above, women, because they have less human capital, will receive less promotions and consequently inhabit commensurately lower job levels 
in exchange for same labor services (Truman and Baroudi, 1994). Bramer, Andrew and Rayton (2005) further concluded that Organization justice is directly proportional to evaluating employee performance and is mainly concerned to ensure fair treatment between different gender and race.

In order to improve employee attitude and performance the employees should be selected on the basis of individual disposition (Alanzi, 2009). Female employee's performance, perceived career growth and comfort at job are strongly related with equal job opportunity and indiscriminative work environment (Irfan, Hussain and Yousaf, 2009).Taylor (2008) noted that employee performance evaluation is a tool to ensure whether the employees are treated fairly and demonstrate management is biased or unbiased. Employees may give low level of preference to a current inequality between their efforts and rewards in the form of distributive justice as they anticipate the organization to have most likely distributive injustice in the current exchange association into a justified effort-reward ratio in the future (Hofstede, 1984). Justice perception was positively in relation with job satisfaction, job performance, and attendance in spite of individuals' position on the personality variables, those scoring less on power distance showed stronger effects than those scoring more on power distance. (Lam, Schaubroeck and Aryee, 2002).According to research by Gadot (2007) responsibility lies on the leaders to create an organization ambiance which is reciprocal, fair and fulfilling the expectations and needs of individuals who in terms lead to increased employee performance and organization as a whole. Harris et al. (2008) further states, managing disputes in an organization, line mangers discrimination while handling grievance between employees will lead to poor performance. social closure through discrimination alongside women or minorities is perceived of as a more direct cause? A cause of workplace disparities captured in statistical residuals once other factors have been accounted for (Roscigno, Garcia, and Bobbitt-Zeher, 2007).

Organizational traditions and norms have important impact of employee's job routine (Irfan, Hussain and Yousaf, 2009).even though they are not the only factors determining the results of justice perceptions, difference in workers' preference for meticulous reward allocation rules (e.g., equity versus equality) may somewhat explain difference in the effects of procedural (perceived fairness of the results employees receive) and distributive justice (perceived fairness of the ways used to determine those results) (Lam, Schaubroeck and Aryee, 2002). In Phillips, the Court held that female and male parents should be judged by the same standard, but contradictory family duties may be more applicable to job performance for women than men. So, in contrast to the benefits cases, it is evident that pregnancy and child rearing were conundrums the Courtcould not be easily resolve (Lens, 2003). Hence, it is concluded that healthy firm's culture and supportive work environment are essential attributes to make a workplace where female employees can with motivation and comfort (Irfan, Hussain and Yousaf, 2009).

\section{Culture}

Culture is looked upon as the decorative ways of thinking, reacting, and feeling that are reflected in conventional ideas and values that distinguish members of one human group from other human groups (Hofstede, 1980). These ideologies are frequently beneath organizational members' awareness and may not be shared by all members; however, they continue to motivate some behaviors while constraining others (Hass and Huwang, 2007). Culture in this sense, involves styles of learning and life that run oppose to the negative effects of modernization (Borofsky et al, 2001). Cultures move and alter and a variety of subcultures may subsist, both reflecting and exercising power relations within a firm. The organizational culture idea also proposes that important events within organizations are often vague and unsure and that the same events may mean different things to diverse people (Lewis, 2003).Differences in culturally based values may be likely to persuade individual reactions to perceptions about the workplace environment through the mediating influence of expectancies and result valences. Employees may be more encouraged and pleased by a meticulous practice simply because it is regular with their values. (Lam, Schaubroeck and Aryee, 2002). Representations of femininity and masculinity are understood in numerous accounts of the cultural (Meanings of gentrification) (Bondi, 1991). High masculinity cultures such as Germany, Japan and the United States are likely to have more sex-differentiated work-related structures with certain jobs almost whole assigned to women and others to men (Tosi and Greckhamer, 2004). Similarly, the cultures of the majority work organizations stay grounded in values and beliefs that strengthen the division of work and family life ("the doctrine of separate spheres") and replicate men's dominance and advantage in the labor market ("masculine hegemony").(Hass and Huwang, 2007).

The conventional stereotypes, organizational culture, poor literacy rates, and societal barriers for women are the main reason for low contribution in the labor force in rising countries. (Irfan, Hussain and Yousaf, 2009).Organizational culture is found to be measurable and to be related to important organizational outcomes (Denison and Mishra, 1995). To comprehend gender-based discrimination requires awareness to "intra-family" or "intra-household" distributions. Economists have not been inclined to focus on whether and how income received by one member of a household is communal among the many members of that household. (Hicks, 2002). 
Cultural representations of legislation and women on family law, reproductive rights, and women's rights imitate the significance of gender in politics and ideology and signal the political agenda of revolutionaries and government. Whether political discourses support women's liberation and equality, or whether they adore tradition, morality, the family, and difference, the point is that political ideologies and practices are gendered, and that social alteration and state-building requires changes in gender relations as well as new class configurations and property relation (Moghadam,1995). Though management teams may encourage greater participation by lowering structural barriers? For example, by flattening hierarchy and promoting cross-functional task sharing? Cultural aspects of teamwork may work against women's full participation (Ollilainen and Calasanti, 2007). To make a multicultural and comprehensive organizational culture it is required to generate a work environment that is free from any kind of harassment and is based on respect for all individuals of sex, gender, class, race, social or cultural origin, disability, religion, lifestyle, organizational level, circum stances, etc. (a basic requirement of joint recognition) (Pless and Maak,2004). There exists a deep cultural root in the male attitudes of Pakistani men towards women; these attitudes are encouraged by the economic factor. The rate of contribution of women in the modern sector is very low, even by Asian standards. However, women offer a significant connection in the productive process, with almost the whole burden for the household sector falling on their shoulders. (Izzud-Din Pal, 1990). Using difference theory frame, the Court clearly recognized that culture-based disputes result in women's jobs being less valued than men's and that the equality therapy, equal pay for equal work, doesn't give a solution (Lens, 2003). Hence actions are being taken place all over the world in order to reduce differences between genders within and outside organizations.

Hofstede's (1984) Culture's Consequences give us a way towards the field to study international organizations. Through his experimental data analysis, he concluded that "organizations are cultural-bounded", he also identified four organization related dimensions of culture, including power distance, uncertainty avoidance, individualism, and masculinity, to examine work-related cultural values in different countries. The first dimension, power distance, refers to the distribution of power unequally between management and subordinates. In high power distance organizations, organizational hierarchy is noticeable clearly. There is a line between managers and subordinates. Different from high power distance organizations, low power distance organizations tend to have a plane organizational structure. The second dimension, uncertainty avoidance, refers to people's forbearance of ambiguity. In high uncertainty avoidance organizations, there are more written rules in order to reduce uncertainty. In low uncertainty avoidance organizations, there are smaller number of written rules and rituals. The third dimension which focus on how people value themselves and their organizations/ groups in which they work known as Individualism-Collectivism. Those who are more concerned about self actualization and career advancement tends to have high individualism, while those who are concerned about organizations wellbeing/benefits tends to have low individualism. The fourth and the last dimension is Masculinity (MAS) expressed as roles of genders in organization. Wu, 2008 further states that Masculinity refers to probable gender roles anticipated by leaders Organizations where only few women are privileged to get higher positions and better paying jobs are considered as high MAS organizations, where as organizations where women are fortunate to get more impartial organization status are considered as low MAS organizations (Hofstede, 1984). Therefore we took culture as a moderating variable between dependent and independent variable.

H4: Culture moderates relationship between gender discrimination and organizational commitment. H5: Culture moderates relationship between gender discrimination and employee performance.

\section{Research methodology:}

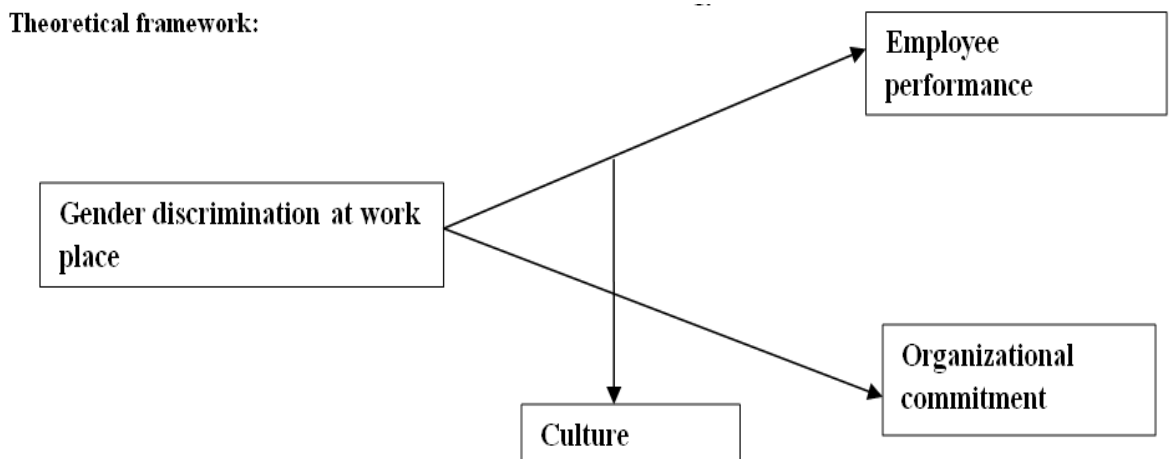




\section{Research instrument:}

\section{Data Analysis:}

Primary data was collected through self administered questionnaires. Using five likertscale, information from 166 respondents was collected. 200 questionnaires were float and 166 were received (response rate: $83 \%$ ). The purpose of the research was to test hypothesis and the type of investigation was co-relational study. The inference of our study was moderate for workers in banks and unit of our analysis was individuals working in banks.

\section{Pilot study:}

In order to ensure that the scales used in the formal study are statistically reliable, a pilot study of few employees from private banks of Pakistan was conducted in June 2011. In those banks 25 questionnaires were distributed. The total number of questionnaires received back was 23 (response rate: 92\%). The questionnaire was designed in English. The reliability results demonstrated that one variable had low reliability scores and remaining all three variables had high reliability. The reliability score for gender discrimination was 54.7 and employee performance, organizational commitment and culture had 77.9, 81.2, and 85.7 respectively.

\section{Population and sampling:}

Population for the study includes employees working in private banks of Pakistan. Sample was collected on the basis of convenient sampling technique and the type of sampling was non probability sampling. Out of 166, 112 were male and 54 were females as males are twice than females in banks. The age of 88 respondents lie among 25-30, 36 were among 21-25 and 36 were among 30-35 and only 6 exceed this age. Mostly respondents' education was between graduation and post graduation. All of our respondents were employed in banks. The sample characteristics are described in following table.

\begin{tabular}{|c|c|c|c|}
\hline Demographics & & Frequency & Percentage \\
\hline \multirow{4}{*}{ Gender } & Male & 112 & 67.5 \\
\cline { 2 - 4 } & Female & 54 & 32.5 \\
\hline \multirow{4}{*}{ Age } & 20 or below & 0 & 0 \\
\cline { 2 - 4 } & $21-25$ & 36 & 21.7 \\
\cline { 2 - 4 } & $26-30$ & 88 & 53.0 \\
\cline { 2 - 4 } & $31-35$ & 36 & 21.7 \\
\cline { 2 - 4 } & $36-40$ & 2 & 1.2 \\
\cline { 2 - 4 } & 41 or above & 4 & 2.4 \\
\cline { 2 - 4 } & Intermediate & 8 & 4.8 \\
\cline { 2 - 4 } & Bachelors & 24 & 14.5 \\
\cline { 2 - 4 } & Masters & 130 & 2.4 \\
\hline \multirow{3}{*}{ Education } & MS or above & 4 & 100 \\
\hline
\end{tabular}

\section{Construct items:}

\section{Gender discrimination:}

(Pang and Huang, 2010) he explained gender discrimination is a kind of worldwide phenomenon which prevails in our daily life and workplace. Women are sometimes treated unjustly and unevenly. This results in women with low income level and positions with same qualification and skills. This slows down the economic efficiency as female abilities are not valued in the best way.

\section{Employee performance:} leave the job.

(Low et al, 2000)Higher levels of employees' job satisfaction will lead towards the lower intention to

\section{Organizational commitment:}

(Low et al, 2000) Higher levels of employees' organizational commitment will leads towards less switching intentions.

\section{Culture (masculinity):}

(Wu, 2006) It is one of four cultural dimensions given by Hofstede which refers to the expected gender roles in leadership expectation. A higher score on masculinity means that members prefer men to have authority and control and expect men to be effective leaders in organizations. 
Outcomes of Gender Discrimination, a Study of Female Workers in Banking Sector of Pakistan.

Correlation

\section{Results}

\begin{tabular}{|l|l|l|l|}
\hline Variable & Mean & Std. deviation & Correlation \\
\hline Gender discrimination & 3.3027 & .55804 & 1 \\
\hline Employee Performance & 3.8527 & .48904 & .069 \\
\hline $\begin{array}{l}\text { Organizational } \\
\text { Commitment }\end{array}$ & 3.6519 & .51080 & .098 \\
\hline Culture & 3.3108 & .93069 & -0.05 \\
\hline
\end{tabular}

Correlation analysis measures strength of relationship between variables. The results of correlation show that there is a very weak positive relationship of gender discrimination with employee performance and organizational commitment i.e. .069 and .098 respectively. However, there is a negative relationship between culture and gender discrimination i.e. -0.05 which is less than 1 . Mean of the variables show that most of the people in banking sector of Pakistan don't think that there is gender discrimination in their organizations as shown by average negative response for discrimination. Most of the employees are committed and are performing up to their best. According to the results, culture also has negative relation to gender discrimination.

\section{Regression}

\begin{tabular}{|l|l|l|l|l|l|l|}
\hline Variable & R & R square & t-value & Beta & p-value & regression \\
\hline $\begin{array}{l}\text { Gender } \\
\text { discrimination } \\
\text { with employee } \\
\text { performance }\end{array}$ & 0.069 & 0.005 & 0.89 & 0.069 & 0.375 & $\begin{array}{l}\text { Hypothesis } \\
\text { rejected }\end{array}$ \\
\hline $\begin{array}{l}\text { Gender } \\
\text { discrimination } \\
\text { with } \\
\text { organizational } \\
\text { commitment }\end{array}$ & 0.098 & 0.010 & 1.259 & 0.098 & 0.210 & $\begin{array}{l}\text { Hypothesis } \\
\text { rejected }\end{array}$ \\
\hline
\end{tabular}

Regression analysis is helpful to see impact of gender discrimination on employee performance and gender discrimination on organizational commitment. $\mathrm{R}$ square shows the impact of gender discrimination on employee performance is .005 in case of employee performance as dependent variable which shows a very weak combine impact of both and 0.010 in case of organizational commitment only which is slightly more than with employee performance but still very weak. As t-value is less than 2 and level of significance is more than .05 it shows that both hypothesis are rejected.

\begin{tabular}{|c|c|c|c|c|c|}
\hline \multicolumn{6}{|c|}{ Moderated regression analysis } \\
\hline Predictors & M1 & M2 & M3 & R square & $\begin{array}{l}\text { Rsquare } \\
\text { change }\end{array}$ \\
\hline \multicolumn{6}{|l|}{$\begin{array}{l}\text { Gender } \\
\text { discrimination }\end{array}$} \\
\hline $\begin{array}{l}\text { Step : Control } \\
\text { variables }\end{array}$ & & & & .044 & .044 \\
\hline Age & -.102 & -.053 & -.050 & & \\
\hline Gender & -.008 & .080 & .080 & & \\
\hline Education & -.203 & -.187 & -.185 & & \\
\hline $\begin{array}{ll}\text { Step } & \text { 2: } \\
\text { Control } & \\
\text { variables } & \end{array}$ & & & & 0.093 & 0.049 \\
\hline $\begin{array}{l}\text { Gender } \\
\text { discrimination }\end{array}$ & & .075 & $\begin{array}{l}.009 \\
-.09\end{array}$ & & \\
\hline Culture & & .230 & 0.140 & & \\
\hline $\begin{array}{l}\text { Step 3: } \\
\text { Multiplied } \\
\text { value GD and } \\
\text { CL }\end{array}$ & & & 0.126 & 0.094 & 0.002 \\
\hline
\end{tabular}


Outcomes of Gender Discrimination, a Study of Female Workers in Banking Sector of Pakistan.

\begin{tabular}{|l|l|l|l|l|l|}
\hline Predictors & M1 & M2 & M3 & R square & R square change \\
\hline Gender discrimination & & & & & \\
\hline Step : Control variables & & & & 0.027 & 0.027 \\
\hline Age & -.011 & .021 & .035 & & \\
\hline Gender & -.111 & -.059 & -.060 & & \\
\hline Education & -.147 & -.136 & -.128 & & \\
\hline Step 2: Control variables & & & & 0.052 & 0.025 \\
\hline Gender discrimination & & 0.105 & -.244 & & \\
\hline Culture & & 0.136 & -.237 & & 0.028 \\
\hline $\begin{array}{l}\text { Step 3: Multiplied value } \\
\text { GD and CL }\end{array}$ & & & .527 & 0.080 & \\
\hline
\end{tabular}

With $\mathrm{OC}$ as dependent variable

As t-value is less than 2 in the first table i.e. when dependent variable is employee performance t-value is 0.531 and significance value is .596 it shows culture don't moderate between employee performance and gender discrimination. While in case when organizational commitment is dependent variable, $t$ is 2.205 and $p$ is .029 , culture also moderates between organizational commitment and Gender Discrimination. Culture doesn't moderate between gender discrimination and employee performance because of the fact that no individual belonging to any culture and country thinks that he is performing below the standard. Hence they rank their performance as best according to the desired performance of organization. It is due to this reason culture don't have any impact on the relationship between variables. Whereas, culture do moderates between gender discrimination and organizational commitment as employees evaluate their organization according to their way of thinking which varies from culture to culture. Hence Hofstede Theory (1984) of culture affecting perceptions of people is applicable in the case of organizational commitment.

\section{Conclusion and Discussions:}

The results of the study take us to the different dimension of gender discrimination. Pakistan is considered to be one of the top most countries with respect to discrimination to females but our results show a different side of picture. We took data from the educated community, which have different perspective for females. According to most of them, female are also capable to perform equally as males do.

Some of the people think that discrimination is embedded in our society so much that people don't perceive discrimination. Males think it is their right to have upper hand and females also think that males should have dominating position. The research on gender discrimination has a gap which we identified in our study. Discrimination is not always negative, sometimes it is positive in a sense that females are given lenience at work place as they have their family burdens plus they are delicate as compare to man. It is Pakistani culture that give female such type of leverages like they cannot work for more than 9 hours a day, no night shifts are given to female employees, no overtime is imposed on them, paid maternity leaves etc. which are not applicable to men.

Another advantage to females is that they are respected at work place regardless of their designation. Women are given administrative jobs while men have to do field work as well. Some organizations also provide transportation (pick and drop service) to their female employees. It is due to the following reasons most of the people working in banks don't think that there is discrimination to females within their organization.

\section{Limitations:}

Potential limitations of this study include relatively small sample size and as a result, this study cannot be generalized on other sectors of the economy. In fact generalization of the conclusion is still limited due to the sample size. This study covered various organizations and it was focused on one industry only. Sample size should increase and cover more organizations as study centers. The research work was bound to be completed in a certain time, so time limit was a barrier for collecting data on a larger scale from more employees and acquiring more information.

\section{Future implications:}

As previously stated the findings from the study were conflicting with the previous research done in this area. The value of $\mathrm{R}^{2}$ is less so more variables can be added or more complex factors can be added I $\mathrm{n}$ our study. Data collected for this study was from private sector organization. We suggest that future studies in this area be made on public sector organization which might show results completely dissimilar or comparison 
between public and private sector can be done. Perhaps a comparison of women across a wide range of professions could lead us to more generalized issues that all professional women face. Furthermore our research discussed affect of masculinity on relationship of variables future studies are encouraged to deeply explore what other factors can affect this relationship.

\section{References}

[1]. Abbas, M.N. Athar, S.A. and Herani, G. (2010). Gender Based Wage Discrimination and Its Impact on Performance of Blue Collar Workers: Evidence from Pakistan. KASBIT Business Journal, 3(1), 45-63.

[2]. Abdullah et al. (2007). Employee Organisational Commitment InSmes: Evidence From The Manufacturing Sector In Malaysia. International Review of Business Research Papers, 3 (2), $12-26$.

[3]. Acharya, M. and Ghimire, P. (2005). Gender Indicators of Equality, Inclusion and Poverty Reduction: Measuring Programme/Project Effectiveness. Economic and Political Weekly, 44/45(40), 4719-4728.

[4]. Acker, J. (2006). Inequality Regimes Gender, Class, and Race in Organizations. Gender and Society Sage Publications, Inc., 4(20), 441-464.

[5]. Alanzi, N.M. (2009). Work place environment and its impact on employee performance, a study submitted to project management department in Saudi Aramco

[6]. Allen et al. (2006). Making Sense of the Barriers Women Face in the Information Technology Work Force: Standpoint Theory, Self-disclosure, and Causal Maps. Springer Science and Business Media Inc., (54), 831-844.

[7]. Angle, H.L. and Perry, J.L. (2007). An Empirical Assessment of Organizational Commitment and Organizational Effectiveness. Administrative Science Quarterly, 26 (1), 1-14.

[8]. Bateman, T. and Strasser, S. (1984). A longitudinal analysis of the antecedents of organizational commitment. Academy of Management Journal, 21, 95-112.

[9]. Black, S. E. and Brainerd, E. (2004). Importing Equality? The Impact of Globalization on Gender Discrimination. Industrial and Labor Relations Review, 4(57), 540-559.

[10]. Bondi, L. (1991). Gender Divisions and Gentrification: A Critique. Blackwell Publishing on behalf of The Royal Geographical Society (with the Institute of British Geographers), 2(16), 190-198.

[11]. Borofsky, et al. (2001). When: A Conversation about Culture. American Anthropologist, (2)103, 432-446.

[12]. Bramer, S. Millington, A and Rayton, B. (2005). The contribution of corporate social responsibility to organizational commitment. Center for business organizations and society. University of Brath School of management

[13]. Bravo, D. Sanhueza, C. \&Urzúa,S. (2005). Gender discrimination and economic outcomes in Chile,” Inter-American Development Bank, Research Department - Latin American andCaribbean Network Study: Discrimination and Economic Outcomes, draft research paper.

[14]. Buvinić, M. (1997). Women in Poverty: A New Global Underclass. Washington post news week interactive, LLC, 4(108), 38-53.

[15]. D'Amato, A. and Hertzfeldt. R. (2008) Learning Orientation, Organizational Commitment and Talent Retention across Generations: A Study of European Managers. Journal of Managerial Psychology, 23, 929 - 953.

[16]. Day, N.E. and Scheonrada, P. (2000). The relationship among reported disclosure of sexual orientation, anti discrimination policies, top management support and work attitudes of gay and lesbian employees. Personnel Review, 29 (3), 346-363.

[17]. Dension, D.R. and Mishra, A.K. (1995). Toward a Theory of Organizational Culture and Effectiveness. INFORMS, 2(6), 204-223.

[18]. Deutsch, F.M. (2007). Undoing Gender. Sage Publications Inc., 1(21), 106-127.

[19]. Dukes et al. (2003). Betty dukes, et al. V. Wal-mart stores, inc.Expert report of William t. Bielby, PhD.

[20]. Ekmekçi, A.K. (2010). A study on involvement and commitment of employees in Turkey. Journal of Public Administration and Policy Research, 3(3), 68-73.

[21]. Ensher, E.A. Vallone, E.G. and Donaldson, S.I. (2001). Effects of Perceived Discrimination on Job Satisfaction, Organizational Commitment, Organizational Citizenship Behavior, and Grievances. Human resource development quarterly, 12(1).

[22]. Gadot, E.V. (2007). Leadership style, organizational politics, and employees' performance. Personnel Review, 36 (5), 661-683.

[23]. Gelfand, M.J. Nishii, L.H. Raver, J.L. \& Schneider, B. (2007). Discrimination In Organizations: An Organizational-Level Systems Perspective.CAHRS Working Paper Series, Paper 470, Working Paper, $07-08$.

[24]. Harris et al. (2008). Small firms and workplace disputes resolution. Acas Research and Evaluation Section, 01-08.

[25]. Hass, L. and Hwang, P. (1995). Company Culture and Men's Usage of Family Leave Benefits in Sweden. Family Relations, 1(44), 28-36.

[26]. Hass, L. and Hwang, P. (2007). Gender and Organizational Culture: Correlates of Companies' Responsiveness to Fathers in Sweden. Sage Publications, Inc., 1(21), 52-79.

[27]. Hicks, D. A. (2002). Gender, Discrimination, and Capability: Insights from Amartya Sen. The Journal of Religious Ethics, 1(30), 137-154.

[28]. Hofstede, G. (1980). Culture's consequences: International differences in work-related values. International journal of intercultural relations, 3(10), 301-320.

[29]. Huffman, M. L. and Cohen, P. N. (2004). Sociological Forum, Occupational Segregation and the Gender Gap in Workplace Authority: National Versus Local Labor Markets.Plenum Publishing Corporation, 1(19), 121-147.

[30]. Irfan, S. M., Hussain, T. and Yousaf, I. (2009). Organizational Culture: Impact on Female Employees' Job Performance. Journal of Quality and Technology Management, 11(5), 1-16.

[31]. Jain, R. (2008). Employee Performance Assessment in Quality Assurance. Master's Projects. San Jose State University, Paper 84.

[32]. Jarrell, S.B. and Stanley, T.D. (2004). Declining Bias and Gender Wage Discrimination? A Meta-Regression Analysis. The Journal of Human Resources, 3(39), 828-838.

[33]. Kelkar, G. (2005). Development Effectiveness through Gender Mainstreaming: Gender Equality and Poverty Reduction in South. Economic and Political Weekly, 44/45(40), 4690-4699.

[34]. Khera, S.N. (2010). Human Resource Practices and their Impact on Employee Productivity: A Perceptual Analysis of Private, Public and Foreign Bank Employees in India. DSM Business Review, 2 (1).

[35]. Lam, S.S.K., Schaubroeck, J. and Arye, S. (2002). Relationship between Organizational Justice and Employee Work Outcomes: A Cross-National study. Journal of Organizational Behavior, 1(23), 1-18.

[36]. Lens, V. (2003). Reading between the Lines: Analyzing the Supreme Court's Views on Gender. Social Science Review, 1(77), 25 50.

[37]. Leonard, J.S., Levine, D.I. and Joshi, A. (2004). Do Birds of a Feather Shop Together? The Effects on Performance of Employees' Similarity with One Another and with Customers. Journal of Organizational Behavior, 6(25), 731-754. 
[38]. Lewis, D. (2003). NGOs, Organization Culture, and Institutional Sustainability.American Academy of Political and Social Science, Vol. (590), 212-226.

[39]. Lippert-Rasmussen, K. (2006). The Badness of Discrimination, Ethical Theory and Moral Practice, Springer Stable, 2(9), $167-185$.

[40]. Machin, M.A.andBannon, S.F. (2005). Australian public sector employees' commitment to organisational change. In m. Katsikitis (ed.), proceedings of the $40^{\text {th }}$ Aps annual conference, melbourne, victoria: australian psychological society, $163-167$.

[41]. Malik, M.E. Ghafoor, M.M and Naseer, S. (2005). Organizational effectiveness: a case study of telecommunication and banking sector of Pakistan. Far East journal of psychology and business, 2 (1).

[42]. McDowell, L. and Court, G. (1994). Gender, Power, and Sexuality in Merchant Banking. Economic Geography, 3(70), $229-251$.

[43]. Moghadam, V.M. (1995). Gender and Revolutionary Transformation: Iran 1979 and East Central Europe 1989. Gender and SocietySage Publications Inc., 3(9), 328-358.

[44]. Öhman et al. (2007). Measuring the gender gap in organizations. Emerald group publishing limited 1-20.

[45]. Onay, M. Unirversitedi, C. and Okulu, U. (2009). The consequences of perceived gender discrimination and an empirical research.Ege Academic Review, 9 (4), 1101-1125.

[46]. Oswald, D.L. and Lindstedt, (2006). The Content and Function of Gender Self-stereotypes:

[47]. Pal, I. (1990). Women and Islam in Pakistan. Middle Eastern Studies Taylor \& Francis, Ltd., 4(26), $449-464$.

[48]. Pang, T. and Huang, S. (2010). The impact of education, law and family factors influence of gender discrimination in China.University of Gävle, Department of Business and Economic Studies, 38.

[49]. Pheng, L.S. and Yuquan, S. (2002). An exploratory study of Hofstede's cross-cultural dimensions in construction. Emerald insight, 1(40), 7-16.

[50]. Pless, N. M. and Maak, T. (2004). Building an Inclusive Diversity Culture: Principles, Processes and Practice. Journal of Business Ethics, 2(54), 129-147.

[51]. Qureshi, M.I. Zaman, K. and Shah, I.A. (2010). Relationship between Rewards and Employee's Performance in the Cement Industry in Pakistan.Journal of International Academic Research 10 (2).

[52]. Ridgeway, C. and Correll, S.J. (2004). Unpacking the Gender System: A Theoretical Perspective on Gender Beliefs and SocialRelations. Sage Publications, Inc., 4(18), 510-531.

[53]. Roscigno, V. J., Garcia, L.M. and Bobbitt-Zeher, D. (2007). Social Closure and Processes of Race/Sex Employment Discrimination. American Academy of Political and Social Science, (609), 16-48

[54]. Ross, H. (1999). Review: Female Education and Development in Asia. The University of Chicago Press on behalf of the Comparative and International Education Society, 1( 43), 110-116.

[55]. Rossi, A.S. (1984). Gender and Parenthood. American Sociological Review, (1) 49, 1-19.

[56]. Saad, H.S., Samah, A.J.A. and Juhdi, N. (2008). Employees' Perception on Quality Work Life and Job Satisfaction in a Private Higher Learning Institution. International Review of Business Research Papers, 4 (3), 23-34.

[57]. Sattar, A. and Nawaz, A. (2011). Investigating the demographic impacts on the job satisfaction of district officers in the province of kpk, Pakistan. International Research Journal of Management and Business Studies, 1(3), 068-075.

[58]. Schech, S. andDev, S. V. (2007). Gender Justice: The World Bank's New Approach to the Poor?.Taylor \& Francis, Ltd. on behalf of Oxfam GB, 1(17), 14-26.

[59]. Shah et al. (1994). Structural Adjustment, Feminization of Labor Force and Organizational Strategies. Economic and Political Weekly, 18(29), WS39-WS48.

[60]. Shahzad, K. Sarmad, M. Abbas, M. and Khan, M.A. (2010). Impact of Emotional Intelligence (EI) on employee's performance in telecom sector of Pakistan. African Journal of Business Management, 5 (4), 1225-123.

[61]. Taylor, V. (2001). Globalisation, the Disappearing State and Poor Women: A View from the South. Agenda, Agenda Feminist Media, 48, 51-60.

[62]. Tosi, H. L. and Greckhamer, T. (2004). Culture and CEO Compensation. INFORMS, 6(15), 657-670.

[63]. Traylor, T. (2008). Employee performance evaluation: the good, the bad, the ugly. City of Hoston, Department of public work \& engineering, human recourse relations/Employee Relations, 611 Walker.

[64]. True, J. and Mintrom, M. (2001). Transnational Networks and Policy Diffusion: The Case of Gender Mainstreaming. Blackwell Publishing on behalf of The International Studies Association, 1(45), 27-57.

[65]. Truman, G. E. and Baroudi, J.J. (1994). Gender Differences in the Information Systems Managerial Ranks: An Assessment of Potential Discriminatory Practices. Management Information Systems Research Center, University of Minnesota, 2(18), 129-142.

[66]. Warsi, S. Fatima, N. \&Sahibzada, S.A. (2009). Study on Relationship Between Organizational Commitment and its Determinants among Private Sector Employees of Pakistan. International Review of Business Research Papers, 5 (3), 399 - 410.

[67]. WeiBo, Z. Kaur, S. and Jun, W. (2009). New development of organizational commitment: A critical review. African Journal of Business Management, 4 (1), 012-020.

[68]. Weiss, A. M. (1985). Women's Position in Pakistan: Socio cultural Effects of Islamization. Asian Survey, University of California Press, 8(25), 863-880.

[69]. Welle, B. Heilmen, M.E. (2005). Formal and informal discrimination against Women at work the role of gender stereotypes. Research in social issues in Management: managing social and ethical issues in organizations, 5(1), 230-243.

[70]. Wu, M.Y. (2006).Hofstede's Cultural Dimensions 30 Years Later: A Study of Taiwan and the United States. Intercultural Communication Studies XV, Western Illinois University. 